\title{
Heterozigosidade e assimetria do número de hâmulos em operárias adultas de Apis mellifera (Hymenoptera, Apidae)
}

\author{
Marco A. Del Lama ${ }^{1,2}$ \\ Caroline Vivian Gruber ${ }^{1}$ \\ Isabel Cristina de Godóy ${ }^{1}$
}

\begin{abstract}
Aвstract. Heterozygosity and hammuli number asymmetry in adult workers of Apis mellifera (Hymenoptera, Apidae). Relationship between individual heterozygosity at particular loci (Mdh-1, Hk-1 ou Pgm-1) or average heterozygosity of the colony and asymmetry of the hammuli number of right and left wings was verified on adult workers of five Africanized and five European colonies of Apis mellifera. Our results demonstrated the importance of statistical tests to verify the type of asymmetry of the character studied and they did not validate the assumption that uni or multiloci heterozygosity has a positive effect on developmental stability.
\end{abstract}

KeYwords. Apis mellifera; developmental homeostasis; fluctuating asymmetry; hammuli number; heterozygosity.

\section{INTRODUÇÃO}

Homeostasia do desenvolvimento (HD) é definida como a capacidade do organismo em resistir a distúrbios genéticos e ambientais, durante o seu desenvolvimento, via mecanismos "tamponantes", para produzir um fenótipo pré-determinado dentro da variação normal de expressão (WADDINGTON 1942; LERNER 1954). Ela é constituída de dois componentes: canalização e estabilidade do desenvolvimento (ED). A canalização é o mecanismo pelo qual a variação do fenótipo é limitada a uma ou poucas formas, sob um conjunto de condições genéticas e ambientais, reduzindo o efeito destas sobre o desenvolvimento. Se a canalização não atuar apropriadamente, o organismo estará suficientemente vulnerável para divergir para uma trajetória diversa da original. A estabilidade do desenvolvimento assegurará, então, esta canalização na ocorrência de "acidentes", reduzindo a influência de perturbações genéticas ou ambientais sobre o desenvolvimento.

Nos organismos que possuem simetria bilateral, ocorre uma correlação das características pares entre os lados do indivíduo. Estas características estão sob o controle de mecanismos genéticos e de ambiente idênticos e, por esta razão, devem exibir total semelhança bilateralmente, a não ser que alguma perturbação prejudique a canalização. Como tais distúrbios são casuais e a expressão média das características é simétrica, ocorre uma distribuição normal dos pontos de assimetria ao redor de zero. A assimetria de um indivíduo serve, portanto, como uma medida do quanto ele conseguiu tamponar seu desenvolvimento contra condições estressantes. Esta ausência ou alteração de uma ou mais características em um dos lados foi designada de assimetria flutuante, AF, e, por estar inversamente correlacionada à $\mathrm{HD}$, freqüentemente ela é utilizada para se estimar a estabilidade do desenvolvimento (VAN VAlen 1962).

Outros tipos de assimetria ocorrem na natureza e são consideradas formas de assimetrias adaptativas ou direcionais. A assimetria direcional ocorre quando existe a tendência de que a característica se desenvolva mais de um lado do que do outro do plano de simetria (VAN VALEN 1962). A anti-simetria ocorre quando uma característica é maior em um lado do que do outro, mas não há a tendência de que um determinado lado seja sempre o maior na população. Em certos casos, a assimetria direcional (Graham et al. 1993; Møller 1994) e a anti-simetria (MCKenZie \& Clarke 1988; Leary \& AlLENDORF 1989) podem ser utilizados como estimadores de HD.

A base genética da homeostasia do desenvolvimento tem sido atribuída à coadaptação genômica e/ou à heterozigosidade. A coadaptação genômica é resultante do balanço das combinações alélicas dentro e entre os diferentes cromossomos, estabilizado durante a história evolutiva do organismo via seleção natural (MATHER 1953; THODAY 1955;

1. Departamento de Genética e Evolução, Universidade Federal de São Carlos. Rodovia Washington Luiz km 235, $13565-905$ São Carlos-SP, Brasil.

2. Endereço eletrônico: dmdl@power.ufscar.br 
Tabela I. Média, variância e amplitude de variação do número de hâmulos das asas direita (dir), esquerda (esq) e da diferença entre elas (d - e), em colônias de abelhas Africanizadas e Européias.

\begin{tabular}{|c|c|c|c|c|c|c|c|c|c|}
\hline \multicolumn{5}{|c|}{ Africanizadas } & \multicolumn{5}{|c|}{ Européias } \\
\hline col. & & Média & Var. & Amplitude & col. & & Média & Var. & Amplitude \\
\hline \multirow[t]{3}{*}{18} & dir & 20,838 & 2,416 & $17-26$ & 48 & dir & 20,686 & 2,508 & $16-25$ \\
\hline & esq & 20,713 & 1,929 & $17-24$ & & esq & 20,314 & 2,914 & $16-24$ \\
\hline & d-e & 0,125 & 2,288 & $-3-+5$ & & $d-e^{2}$ & 0,357 & 3,131 & $-3-+4$ \\
\hline \multirow[t]{3}{*}{$\mathrm{s} / \mathrm{n}$} & $\operatorname{dir}$ & 20,973 & 3,663 & $17-25$ & 40 & dir & 20,284 & 2,570 & $17-24$ \\
\hline & esq & 20,793 & 3,329 & $17-26$ & & esq & 20,597 & 2,820 & $16-24$ \\
\hline & d-e & 0,180 & 2,367 & $-4-+5$ & & d-e & 0,313 & 2,340 & $-4-+4$ \\
\hline \multirow[t]{3}{*}{61} & $\operatorname{dir}$ & 20,363 & 2,563 & $17-25$ & 20 & $\operatorname{dir}$ & 20,689 & 2,318 & $17-24$ \\
\hline & esq & 20,363 & 2,437 & $16-25$ & & esq & 20,508 & 2,754 & $17-25$ \\
\hline & d-e & 0,000 & 2,785 & $-4-+4$ & & d-e & 0,180 & 3,050 & $-2-+4$ \\
\hline \multirow[t]{3}{*}{39} & $\operatorname{dir}$ & 20,773 & 2,683 & $17-25$ & 18 & dir & 21,406 & 2,404 & $18-26$ \\
\hline & esq & 20,682 & 2,150 & $17-24$ & & esq & 21,172 & 2,716 & $16-24$ \\
\hline & d-e & 0,091 & 2,336 & $-4-+5$ & & d-e & 0,234 & 2,976 & $-4-+4$ \\
\hline \multirow[t]{3}{*}{57} & dir & 20,375 & 3,149 & $17-25$ & 42 & dir & 21,051 & 2,463 & $15-25$ \\
\hline & esq & 20,163 & 2,604 & $17-25$ & & esq & 20,847 & 2,304 & $18-25$ \\
\hline & d-e & 0,202 & 2,939 & $-6-+4$ & & d-e & 0,203 & 2,854 & $-4-+4$ \\
\hline
\end{tabular}

Dobzhansky 1970). Desta forma, a homeostasia do desenvolvimento é o resultado da ação conjunta de genes selecionados para interagir harmoniosamente, produzindo um padrão "organizado" de desenvolvimento.

Vários estudos têm evidenciado que a homeostasia é positivamente afetada pela maior heterozigosidade. A maior HD dos heterozigotos seria explicada em razão da maior eficiência bioquímica resultante da interação de alelos diferentes nestes indivíduos (LERNER 1954; SOULÉ 1979).

A relação entre heterozigosidade e assimetria em caracteres de asas de operárias adultas de Apis mellifera (Latreille, 1804) tem sido estudada em colônias com diferentes graus de endocruzamento, ploidia e hibridização e resultados discrepantes foram relatados (BRÜCKNER 1976; CLARKE et al. 1992; Sмiтн et al. 1997). A heterozigose no loco $M d h-1$ foi positivamente associada à HD em caracteres de venação das asas de Apis mellifera (MitTon 1993; Messier \& MitTon 1996), embora tal associação não tenha sido confirmada em trabalho posterior (ClaRKE \& OLdROYD 1996).

O presente trabalho foi conduzido com os seguintes objetivos: 1) verificar se o "número de hâmulos" em asas de Apis mellifera apresenta assimetria do tipo flutuante, constituindo-se em método fácil e seguro de estimar a homeostasia do desenvolvimento; 2) estimar o efeito da homo/ heterozigose em locos enzimáticos específicos ( $M d h-1, H k-1$, Pgm-1) sobre a assimetria individual; 3 ) verificar a correlação entre a heterozigosidade média da colônia, estimada através de marcadores bioquímicos (Mdh-1,Hk-1, Pgm-1,Est-1 e Est-3), e os níveis de assimetria da colônia para este caráter.

\section{MATERIAL E MÉTODOS}

Foram analisadas as asas de operárias adultas de Apis mellifera de cinco colônias Africanizadas mantidas no apiário do Departamento de Genética da Faculdade de Medicina de Ribeirão Preto (USP) e amostras de cinco colônias de abelhas de origem Européia (doravante denominadas colônias Européias), provenientes da introdução neste mesmo apiário de rainhas de Pullman (WA/USA) naturalmente fecundadas.

Análise morfométrica - Para a análise morfométrica, as asas direita e esquerda de operárias adultas de cada colônia foram montadas entre lâminas de vidro. A contagem do número de hâmulos foi realizada sob microscópio estereoscópico.

Análise aloenzimática - Para estimar as heterozigosidades intra-loco ( Hi ) e média ( $\mathrm{H}$ ), extratos de tórax de operárias adultas foram analisados através de eletroforese horizontal em gel de amido (Del Lama et al. 1985, 1988, 1990; Loвo et al. 1989) para os seguintes sistemas aloenzimáticos: malato desidrogenase (Mdh) nas amostras Européias e Africanizadas; esterases (Est-1 e Est-3), fosfoglucomutase (Pgm) e hexoquinase (Hk) nas amostras Africanizadas.

Análise estatística - O número médio de hâmulos das asas direita e esquerda das abelhas Africanizadas foi comparado com o número médio apresentado pelas abelhas Européias através de um teste t. Para tal análise, 80 operárias de cada uma das cinco colônias Africanizadas e 59 operárias de cada uma das cinco colônias Européias foram agrupadas.

Para verificar se a distribuição dos desvios da simetria $\left(\mathrm{d}_{\mathrm{i}}-\mathrm{e}_{\mathrm{i}}\right)$ diferia da normalidade e se o centro desta distribuição era igual a zero, condições que caracterizam a assimetria flutuante, foram utilizados o teste de Kolmogorov - Smirnov e $o$ teste $t$, respectivamente.

Para a estimativa da assimetria de cada colônia foi utilizada 
Tabela II. Valores de $d$ (teste de Kolmogorov-Smirnov) e $t$ (teste t) para verificação de normalidade e média zero, respectivamente, das distribuições dos desvios do número de hâmulos entre as asas direita e esquerda de operárias adultas de colônias Africanizadas e Européias de Apis mellifera.

\begin{tabular}{|c|c|c|c|c|c|c|c|}
\hline \multicolumn{4}{|c|}{ Africanizadas } & \multicolumn{4}{|c|}{ Européias } \\
\hline col. & & $d$ & $t$ & col. & & $d$ & $t$ \\
\hline \multirow[t]{3}{*}{18} & dir & $0,158 *$ & - & 48 & Dir & 0,153 & - \\
\hline & esq & $0,182 *$ & - & & Esq & 0,144 & - \\
\hline & d-e & $0,195^{*}$ & 0,739 & & d-e & 0,128 & 1,689 \\
\hline \multirow[t]{3}{*}{$\mathrm{s} / \mathrm{n}$} & dir & 0,116 & - & 40 & Dir & $0,167 *$ & - \\
\hline & esq & 0,123 & - & & Esq & 0,132 & - \\
\hline & d-e & $0,141 *$ & 0,971 & & d-e & 0,166 & $-1,677$ \\
\hline \multirow[t]{3}{*}{61} & dir & $0,170 *$ & - & 20 & Dir & 0,150 & - \\
\hline & esq & $0,159 *$ & - & & Esq & 0,170 & - \\
\hline & d-e & 0,150 & 0 & & d-e & $0,193^{*}$ & 0,806 \\
\hline \multirow[t]{3}{*}{39} & dir & 0,136 & - & 18 & Dir & 0,150 & - \\
\hline & esq & $0,154^{*}$ & - & & Esq & 0,151 & - \\
\hline & d-e & $0,183^{*}$ & 0,558 & & d-e & 0,117 & 1,087 \\
\hline \multirow[t]{3}{*}{57} & $\operatorname{dir}$ & $0,161 *$ & - & 42 & Dir & $0,199 *$ & - \\
\hline & esq & $0,165^{*}$ & - & & Esq & 0,172 & - \\
\hline & d-e & $0,114^{*}$ & 1,201 & & d-e & 0,164 & 0,925 \\
\hline
\end{tabular}

* significante ao nível de $5 \%$

a variância das diferenças no número de hâmulos entre os lados direito e esquerdo dos indivíduos analisados $\left(\operatorname{var}_{\mathrm{de}}\right)$.

Para verificar o efeito da homo ou heterozigose no loco Mdh-1 sobre a assimetria do número de hâmulos nas colônias Africanizadas e Européias foi realizado o teste de Woolf (1955). Nesta análise, foram considerados simétricos os indivíduos cuja diferença entre os lados foi igual a zero, e assimétricos os indivíduos cuja diferença foi diferente de zero. O mesmo teste foi aplicado para se investigar o efeito da homo/heterozigose nos locos Hk-1 e Pgm-1 sobre a assimetria no número de hâmulos verificada nas colônias Africanizadas. Este teste não pode ser estendido aos locos Est-1 e Est-3, em razão de que tais polimorfismos não foram observados na maioria das colônias Africanizadas estudadas.

\section{RESULTADOS}

Na comparação entre o número de hâmulos das asas de operárias adultas, as variâncias encontradas não diferiram de forma significativa nas colônias Africanizadas e Européias ( $\mathrm{F}=$ $0,842, p=1,0$ para asa direita; $F=0,917, p=1,0$ para asa esquerda). $\mathrm{O}$ número de hâmulos não foi significativamente diferente entre as operárias de colônias Africanizadas e Européias $(\mathrm{t}=1,599, \mathrm{p}=0,112$ para asa direita; $\mathrm{t}=-1,385, \mathrm{p}=$ 0,167 para asa esquerda). A média, a variância, a amplitude de variação do número de hâmulos nas asas direita e esquerda e a magnitude da diferença entre as asas estão apresentadas na Tabela I.

Na Tabela II são ilustrados os valores de $d$ estimados para verificação de distribuição normal dos desvios para o número de hâmulos, e os valores de $t$, utilizados para verificar se a distribuição de tais desvios apresentavam média zero. Entre as cinco colônias Africanizadas, apenas uma apresentou distribuição normal, enquanto que em quatro das cinco colônias Européias os desvios apresentaram distribuição normal. $\mathrm{O}$ centro da distribuição dos desvios não diferiu significativamente de zero em todas as dez colônias analisadas.

A heterozigosidade para o loco $M d h-1$ variou de 0,038 0,587 nas colônias Africanizadas e de $0,361-1,0$ nas colônias Européias. Nas abelhas Africanizadas, foram estimadas ainda as heterozigosidades para os locos Hk-1, Pgm-1, Est-1 e Est-3, bem como a heterozigosidade média para esses locos (Tabela III).

Não foi observada correlação significativa entre a variância dos desvios $(\mathrm{d}-\mathrm{e})$ e a heterozigosidade média das colônias Africanizadas $(\mathrm{r}=-0,081, \mathrm{p}=0,897)$.

Não foi encontrada associação através do teste de Woolf entre homo/heterozigose para o loco Mdh-1 e assimetria do número de hâmulos nas dez colônias estudadas. Resultado similar foi encontrado para os locos Hk-1 e Pgm- 1 nas cinco colônias Africanizadas analisadas (Tabela IV).

\section{DISCUSSÃO}

O número médio de hâmulos nas asas de operárias adultas das colônias Africanizadas ou Européias não apresentou diferença significativa. Esta semelhança no número de hâmulos não foi compartilhada pelo tipo de assimetria encontrada nos dois tipos de colônias. Enquanto a colônia 61 (Africanizada) e as colônias 18, 40, 42 e 48 (Européias) apresentaram assimetria flutuante (distribuição normal dos pontos de assimetria ao redor de zero), as colônias Africanizadas 18, 39, 57 e S/N e a colônia 20 (Européia) não apresentaram distribuição normal dos pontos de assimetria, apesar do centro destas distribuições não diferir significativamente de zero. Estas últimas colônias não apresentaram, portanto, assimetria flutuante no senso estrito.

Estes resultados parecem sugerir que em abelhas Européias, a assimetria verificada no número de hâmulos seja do tipo flutuante, enquanto que nas colônias Africanizadas, os desvios encontrados não apontam para este tipo de assimetria. Entretanto, dados de operárias adultas de Apis mellifera obtidas da região de Coyhaique/Chile (de origem Européia) demonstraram que apenas duas dentre quinze colônias analisadas apresentavam assimetria flutuante para o número

Tabela III. Heterozigosidades intralocos e média ( H ) verificadas em colônias Africanizadas e heterozigosidade intraloco de $M d h-1$ em colônias Européias de Apis mellifera.

\begin{tabular}{|c|c|c|c|c|c|c|c|c|}
\hline \multicolumn{7}{|c|}{ Africanizadas } & \multicolumn{2}{|c|}{ Européias } \\
\hline col. & $M d h-1$ & $H k-1$ & Pgm-1 & Est-1 & Est-3 & $\mathrm{H}$ & col. & $M d h-1$ \\
\hline 18 & 0,313 & 0,463 & 0,075 & 0,063 & 0,113 & 0,205 & 48 & 1 \\
\hline $\mathrm{s} / \mathrm{n}$ & 0,482 & 0,536 & 0,116 & 0 & 0 & 0,227 & 40 & 0,448 \\
\hline 61 & 0,038 & 0,525 & 0,063 & 0 & 0,025 & 0,130 & 20 & 0,361 \\
\hline 39 & 0,432 & 0,296 & 0,568 & 0 & 0 & 0,259 & 18 & 0,422 \\
\hline 57 & 0,587 & 0,558 & 0,164 & 0,019 & 0,048 & 0,275 & 42 & 0,525 \\
\hline
\end{tabular}


Tabela IV. Valores das significâncias (sig; gl = 1) e das heterogeneidades (het; $\mathrm{gl}=4$ ) observados nos testes de Woolf para verificação de associação entre simetria do número de hâmulos e homo/heterozigose para os diferentes locos enzimáticos.

\begin{tabular}{cccccc}
\hline & \multicolumn{2}{c}{ Africanizadas } & \multicolumn{2}{c}{ Européias } \\
\cline { 2 - 5 } & sig & het & sig & het \\
\hline simetria x & Mdh-1 & 0,024 & 6,142 & 0,239 & 3,195 \\
& $H k-1$ & 0,080 & 5,199 & - & - \\
& Pgm-1 & 0,121 & 1,202 & - & - \\
\hline
\end{tabular}

de hâmulos (GRUBER, dados não publicados).

$\mathrm{O}$ efeito da heterozigosidade sobre a HD foi investigada nas colônias Africanizadas através da correlação entre $\mathrm{H}$ e a assimetria mensurada através da variância dos desvios absolutos do número de hâmulos. A correlação não significativa obtida indicou que a maior heterozigosidade não influencia positivamente HD em Apis mellifera.

Nossos achados contrastam com os descritos por BRÜKNER (1976), que verificou maior assimetria em machos que nas operárias, maior assimetria em operárias altamente endocruzadas (homozigotas) que em operárias com baixos níveis de endogamia para duas nervuras das asas e para o número de hâmulos. No entanto, Clarke et al. (1992) não encontraram aumento significativo da assimetria flutuante em operárias altamente homozigotas para os caracteres utilizados por BRÜKNER (1976) e outros incluídos na análise.

Não foram encontradas diferenças significativas no nível de assimetria entre indivíduos homo/heterozigotos para os locos Mdh-1 (nas colônias Africanizadas e Européias) e Hk-1 e Pgm-1 (em colônias Africanizadas). Estes resultados indicam que a homozigose ou heterozigose nestes locos não está associada ao nível de assimetria para o número de hâmulos.

Analisando uma colônia de Apis mellifera, Miтton (1993) verificou que indivíduos heterozigotos para $M d h-1$ apresentavam maior assimetria flutuante para uma das cinco nervuras estudadas. Em estudo subsequente, Messier \& Mitton (1996), analisando esta mesma nervura, verificaram assimetria flutuante significativamente menor em operárias heterozigotas do que nas operárias homozigotas para $M d h-1$. Resultados discordantes foram obtidos por CLARKE \& OLDROYD (1996) ao não verificarem associação entre assimetria flutuante para cinco medidas de asas e para o número de hâmulos e a homo/heterozigose para o loco $M d h$ - 1 . Os autores reportaram ainda que a análise dos dados originais de Mitron (1993) com a mesma metodologia estatística utilizada por eles, não confirmava a associação encontrada por aquele autor.

Os resultados do presente trabalho não apóiam, desta forma, a hipótese de que a heterozigosidade em locos específicos (Mdh-1, Hk-1 ou Pgm-1) ou em múltiplos locos (heterozigosidade média) tem efeito positivo sobre a estabilidade do desenvolvimento. No entanto, esta conclusão deve ser considerada com cuidado tendo em vista as seguintes ressalvas:

(1) apesar de diversos autores utilizarem a heterozigosidade média estimada a partir de alguns locos como uma estimativa da variação do genoma, incluindo aqueles que controlam a estabilidade do desenvolvimento (Soulé 1979), este tipo de análise deve ser considerada insuficiente para predizer a heterozigosidade do genoma, mesmo considerando os genes que podem estar em desequilíbrio de ligação com os locos estudados. A estimativa da heterozigosidade real dos indivíduos e colônias requer a análise de um número muito maior de tipos distintos de locos, o que dificulta e/ou inviabiliza este tipo de abordagem;

(2) estudos de malato desidrogenase em abelhas ou de lactato desidrogenase em peixes indicam que diferenças na HD podem ser relacionadas a genótipos específicos de um único loco, devido a diferentes propriedades bioquímicas das variantes produzidas por alelos destes locos (MitTon 1993). No entanto, segundo Clarke \& OldRoyd (1996), embora a Mdh possa ter um papel importante no controle dos mecanismos envolvidos na estabilidade do desenvolvimento, diferenças bioquímicas ou fisiológicas associadas às diferentes aloenzimas não devem ser suficientes para afetar a eficiência destes mecanismos.

Muitos autores têm considerado "a priori" como assimetria flutuante quaisquer desvios observados em um caráter bilateral. Neste trabalho, das dez colônias estudadas, cinco apresentaram AF para o número de hâmulos. Nossos achados reafirmam, assim, a importância da utilização de testes específicos para a verificação do tipo de assimetria apresentado pelo caráter em estudo, corroborando indicação similar de trabalhos prévios (Clarke et al. 1992; Clarke \& OldRoyd 1996; Sмiтн et al. 1997).

Os resultados aqui relatados não apóiam a hipótese de que a heterozigosidade uni ou multilocal influencia positivamente a homeostase do desenvolvimento. A utilização de outros caracteres bilaterais e estimativas de heterozigosidade baseadas em um maior número de locos gênicos são necessárias para que se possa confirmar em Apis mellifera a hipótese de que heterozigosidades mais elevadas estão associadas a menores níveis de assimetria.

\section{REFERÊNCIAS}

BRÜCKNER, D. 1976. The influence of genetic variability on wing asymmetry in honeybees (Apis mellifera). Evolution 30: 100-108.

Clarke, G. M. \& B. P. Oldroyd. 1996. The genetic basis of developmental stability in Apis mellifera II. Relationships between character size, asymmetry and single-locus heterozygosity. Genetica 97: 211224 .

Clarke, G. M.; B. P. Oldroyd \& P. Hunt. 1992. The genetic basis of developmental stability in Apis mellifera: Heterozygosity versus Genic Balance. Evolution 46: 753-762.

Del Lama, M. A.; M. A. Mestriner \& J. C. A. Paiva. 1985. Est-5 and Pgm1: new polymorphisms in Apis mellifera. Revista Brasileira de Genética VIII(1): 17-27.

Del Lama, M. A.; R. A. Figueiredo; A. E. E. Soares \& S. N. Del Lama. 
1988. Hexokinase polymorphism in Apis mellifera and its use for Africanized honeybee indentification. Brazilian Journal of Genetics 11: 287-297.

Del Lama, M. A.; J. A. Lobo; A. E. E. Soares \& S. N. Del Lama. 1990. Genetic differentiation estimated by isozymic analysis of Africanized bee populations from Brazil and from Central America. Apidologie 21: 271-280.

Dobzhansky, T. 1970. Genetics and the Evolutionary Process. New York, Columbia University Press, 505p.

Graham, J. H.; D. C. Freeman \& J. M. Emlen. 1993. Antisymmetry, directional asymmetry and chaotic morphogenesis. Genetica 89: 121137.

Leary, R. F. \& Allendorf, F. W. 1989. Fluctuating asymmetry as an indicator of stress: implications for conservation biology. Trends in Ecology and Evolution 4: 214-217.

Lerner, I. M. 1954. Genetic Homeostasis. London, Oliver and Boyd, $154 \mathrm{p}$.

Lobo, J. A.; M. A. Del Lama \& M. A. Mestriner. 1989. Population differentiation and racial admixture in the Africanized honeybee (Apis mellifera). Evolution 43: 794-802.

MAtheR, K. 1953. Genetic control of stability in development. Heredity 7: $297-336$

McKenzie, J. A. \& G. M. Clarke. 1988. Diazinon resistance, fluctuating asymmetry and fitness in the Australian sheep blowfly. Genetics
77: $385-394$.

Messier, S. \& J. B. Mitton. 1996. Heterozygosity at the malate dehydrogenase locus and developmental homeostasis in Apis mellifera. Heredity 76: 616-622.

Mitton, J. B. 1993. Enzyme heterozygosity, metabolism, and developmental stability. Genetica 89: 47-65.

MølLER, A. P. 1994. Directional selection on directional asymmetry: testes size and secondary sexual characters in birds. Proceedings of the Royal Society London B 258: 147-151.

Smith, D. R.; B. J. Crespi \& F. L. BooksteIn. 1997. Fluctuating asymmetry in the honey bee, Apis mellifera: effects of ploidy and hybridization. Journal of Evolutionary Biology 10: 551-574.

SouLÉ, M. E. 1979. Heterozygosity and developmental stability: another look. Evolution 33: 396- 401.

ThodAY, J. M. 1955. Balance, heterozygosity and developmental stability. Cold Spring Harbor Symposium in Quantitative Biology 20: 318-326.

Van Valen, L. 1962. A study of fluctuating asymmetry. Evolution 16: 125-142.

WadDington, C. H. 1942. Canalization of development and the inheritance of acquired characters. Nature 150: $563-565$.

Woolf, B. 1955. On estimating the relation between blood and disease. Annals of Human Genetics 19: 251-253. 